\title{
Human leukocyte antigen genes may outweigh racial background when generating a specific immune response in sarcoidosis
}

\author{
J. Grunewald, A. Eklund
}

\begin{abstract}
Human leukocyte antigen genes may outweigh racial background when generating a specific immune response in sarcoidosis. J. Grunewald, A. Eklund. (C) ERS Journals Ltd 2001 .

ABSTRACT: Presented is a sarcoidosis patient of African origin, who was adopted at an early age and grew up in Sweden.

This patient displayed an immune response identical to that previously reported in human leukocyte antigen (HLA)-DR17 positive Caucasian sarcoidosis patients in Scandinavia, with T-cell receptor AV2S3 + T-cells accumulating in the lungs. HLA typing also established that she was DR17 positive, which is a rare HLA type for individuals of African origin.

To the authors' knowledge, this specific immune response has not previously been reported in patients of African origin. Moreover, the clinical manifestations of sarcoidosis were similar to those known to be strongly linked to HLA-DR17 in Scandinavians, i.e. with Löfgren's syndrome.

The case presented here suggests certain human leukocyte antigen genes to be strongly linked to specific immune responses that are identical irrespective of the racial background. If such an immune response were important for the subsequent clinical manifestations, this case would argue for the importance of human leukocyte antigen genes in the genetic predisposition to sarcoidosis.

Eur Respir J 2001; 17: 1046-1048.
\end{abstract}

The genetic susceptibility to sarcoidosis is supported by a racial variation in incidence and clinical presentation, and by an increased risk for family members of a primary case. Exposure for an as yet unknown antigen(s) is, however, also considered to be required to develop the disease $[1,2]$. A large body of evidence indicates in particular the human leukocyte antigen (HLA) genes to be important for the genetic predisposition, and certain HLA alleles e.g. HLA-B8, -DR17(3) are known to be associated with the disease and/or its clinical manifestations [3-8]. The function of such disease associated HLA alleles could be to present specific antigenic peptides in a particular way, so that the recognizing T-lymphocytes subsequently will initiate an inflammation with pathological consequences. However, many genes have also been suggested to contribute to a genetic susceptibility, including those involved in antigen presentation and recognition such as transporter associated with antigen processing (TAP) [9], low-molecular-weight polypeptides (LMP) $[10,11]$ and T-cell receptor (TCR) genes [12]. In addition, in sarcoidosis especially, polymorphic genes encoding angiotensin converting enzyme (ACE) [13-16], vitamin D receptor (VDR) [17] and cytokines such as interleukin (IL)- $1 \alpha$ and tumor necrosis factor- $\alpha$
Dept of Medicine, Division of Respiratory Medicine, Karolinska Hospital, Stockholm, Sweden.

Correspondence: J. Grunewald, Lung Research Laboratory L2:01, Karolinska Hospital, S-171 76 Stockholm, Sweden.

Fax: 46851775451

\section{Keywords: Genetic basis of disease} human leukocyte antigen immunology

interstitial lung disease

sarcoidosis

T-cell receptor

Received: October 42000

Accepted after revision November 13 2000

This work was supported by the Swedish Heart Lung Foundation, the Swedish Medical Research Council (Project number 12621), and Karolinska Institutet.
$(\mathrm{TNF}-\alpha)[12,18,19]$ have been implicated to be disease associated.

The case presented here would argue for the HLA genes to mainly contribute to the genetic susceptibility to sarcoidosis. This HLA-DR17 positive patient was of African origin and had an identical immune response to that previously recorded in DR 17 positive Caucasian patients. She also had clinical manifestations similar to those known to be strongly linked to HLA-DR17 in Scandinavians.

\section{Case report}

A 28-yr-old Black-African patient, who was adopted at 6 months of age by Swedish parents and since then has lived in Sweden, was admitted to the clinic with 4-5 months history of symptoms typical of sarcoidosis. The patient stopped smoking 2 yrs prior to admission (2.5 pack-yrs in total). The disease onset was acute, with fever and arthralgias and after $\sim 1$ month erythema nodosum appeared on her lower limbs. She had chest radiographic stage I (bilateral hilar lymphadenopathy without infiltrates), and thus fulfilled the criteria for Löfgren's syndrome. Two 
months after disease onset, she developed bilateral iritis which may occur early on in sarcoidosis but is not a part of the syndrome originally described by S. Löfgren. She also developed a half sided facial paresis. At admission, all symptoms were in remission without any treatment.

Her pulmonary function was normal apart from a slight decrease in diffusion capacity ( $86 \%$ of predicted). Laboratory tests including blood differential count, sedimentation rate, autoantibodies, ACE, electrolytes and liver enzymes were all normal except for initially slightly elevated serum aspartate aminotransferase s-(ASAT) (0.66; normally $\left.<0.6 \mu \mathrm{kat} \cdot \mathrm{L}^{-1}\right)$ and serum gamma glutamyltransferase s-(GT) $(0.9$; normally $\left.<0.8 \mu \mathrm{kat} \cdot \mathrm{L}^{-1}\right)$. These latter values normalized within 2 months. A bronchoscopy was performed and transbronchial biopsies showed occurrence of nonnecrotizing epithelioid cell granulomas, thus supporting the diagnosis. Bronchoalveolar lavage (BAL) was also performed [20] and an increased concentration of BAL cells was found $\left(663.2 \times 10^{6} \cdot \mathrm{L}^{-1}\right.$; normal range in the laboratory $\left.50-150 \times 10^{6} \cdot \mathrm{L}^{-1}\right)$. The BAL differential count showed a slight decrease of alveolar macrophages $(81 \%)$ and an increase of lymphocytes $(18.8 \%)$. The BAL CD4/CD8 ratio was increased 16.5 (normally $<3.5$ ). No micro-organisms could be detected. It was concluded that this patient showed signs of classical Löfgren's syndrome, and in addition developed iritis and neurological symptoms. At follow-up 2 months later, the patient had improved without any treatment except local corticosteroids for her iritis, but 6 months after her first visit she suffered from tiredness, slight weight loss and iridocyclitis, and treatment with systemic corticosteroids was initiated. Her clinical course is currently monitored, and 18 months after the first clinical symptoms of disease she is still on a low dose of oral steroids.

The patient was further characterized immunologically and found to have a significantly increased number of CD4 + BAL T-lymphocytes expressing TCR $\alpha$-chain variable (V) gene segment 2.3 (AV2S3) (19.0\%; normal median value $3.5 \%$ [21]). In peripheral blood, the AV2S3 + T-cell population only made up $4.5 \%$ of CD $4+$ lymphocytes, showing an accumulation of these cells to the lungs of this patient. The HLA type was $\mathrm{A} * 24,33, \mathrm{~B} * 07,58, \mathrm{DRB} 1 * 0301,0404$, DRB3*0202, DRB4*0101, DQA $1 * 0303,0501$ and DQB1*0201, 0401. It is noticeable that at least in certain regions of Africa, the dominating $\mathrm{DRB} 1 * 03$ allele is *0302 rather than *0301 (O. Olerup, Huddinge Hospital, Sweden, personal communication). Thus, this patient expressed an HLA type (DRB1*0301 i.e. DR17) unusual for African individuals but strongly associated with distinct clinical characteristics in Scandinavian patients, i.e. Löfgren's syndrome, and a good prognosis [8]

\section{Discussion}

A number of polymorphic genes may contribute to the genetic background that is known to influence the incidence as well as clinical manifestations of sarcoidosis. The present case is important because it suggests the HLA genes confer the ability to generate a specific immune response towards a presumed sarcoidosis associated antigen, irrespective of the racial background of the patient. Such an immune response may subsequently be important for the inflammation and for clinical manifestations of the disease.

The distinct and local immune response, i.e. AV2S3 + CD4 + T-cells accumulating in the lungs, was previously identified only in HLA-DR17 positive Scandinavian Caucasian sarcoidosis patients [20, 22]. In fact, the association between lung accumulated CD4 + AV2S3 + T-lymphocytes and HLA-DR17 in Scandinavian patients with pulmonary sarcoidosis is extremely strict, provided there is an active disease [20, 22]. Moreover, BAL AV2S3 + T-cells were recently found to correlate with clinical features of the disease [23] and to express a panel of activation markers indicative of select stimulation of this particular subset [24]. Sequencing of the TCR alpha chains also supported the concept that these cells have been stimulated by an as yet unknown antigen [25]. These results altogether strongly argue for the existence of a specific sarcoidosis associated antigen, which is presented by HLA-DR17 molecules and recognized by AV2S3 + T-cells. The presented case was born in Africa but grew up in Sweden from 6 months of age, and was, therefore, probably exposed to a postulated "sarcoidosis-antigen" in Sweden. From this point of view, it would be interesting to analyse the specific immune response in HLA-DRB1*0301 (DR17) positive sarcoidosis patients living outside Scandinavia, to find out whether this genetic background would be linked to the same immune response also in other parts of the world. To the authors' knowledge, an analysis specifically of the AV2S3 + T-cells in BAL fluid of African American sarcoidosis patients has not been reported. HLA-DRB $1 * 0301$ is part of the common Caucasian "autoimmune" HLA haplotype A*01, B*08, DRB1*0301, and it seems unusual in African individuals. The isolated expression of DRB $1^{*} 0301$ in this patient, but not $A^{*} 01$ or $B * 08$, would support the importance of especially the HLA-DR-DQ region in the genetic predisposition to sarcoidosis.

Finally, it was interesting to note that the clinical manifestations of this case were consistent with Löfgren's syndrome, which is common in Scandinavia [26], and also linked to HLA-DR17 [8]. Whether the present case will develop a benign form of the disease, as reported previously on HLA-DR17 positive Scandinavian patients [8], remains to be seen. This particular group of Scandinavian patients will almost always experience a total remission within 2 yrs if they had a disease onset with classical Löfgren's syndrome [8]. The present case had, besides Löfgren's syndrome, iritis and some neurological symptoms, which may indicate a more protracted disease course. Usually, Löfgrens's syndrome per se does not call for oral steroid treatment, however this patient was treated because she had recurrent iritis and general malaise.

It is concluded that sarcoidosis patients with matching human leukocyte antigen types are capable of mounting identical immune responses, irrespective of their racial background, against what is speculated could be a specific sarcoidosis antigen. 
Acknowledgements. The authors wish to express their gratitude to $\mathrm{M}$. Berlin, Karolinska Hospital, and to O. Olerup, Huddinge Hospital.

\section{References}

1. American Thoracic Society. Statement on Sarcoidosis. Am J Respir Crit Care Med 1999; 160: 736-755.

2. Newman LS, Rose CS, Maier LA. Sarcoidosis. $N$ Engl $J$ Med 1997; 336: $1224-1234$.

3. Hedfors E, Lindstrom F. HLA-B8/DR3 in sarcoidosis. Tissue Antigens 1983; 22: 200-203.

4. Gardner J, Kennedy HG, Hamblin A, Jones E. HLA associations in sarcoidosis: a study of two ethnic groups. Thorax 1984; 39: 19-22.

5. Lenhart K, Kolek V, Bartova A. HLA antigens associated with sarcoidosis. Dis Markers 1990; 8: $23-29$.

6. Pasturenzi L, Martinetti M, Cuccia M, Cipriani A, Semenzato G, Luisetti M. HLA class I, II and III polymorphism in Italian patients with sarcoidosis: the Pavia-Padova Sarcoidosis Study Group. Chest 1993; 104: $1170-1175$

7. Martinetti M, Tinelli C, Kolek V, et al. "The sarcoidosis map": a joint survey of clinical and immunogenetic findings in two European countries. Am J Respir Crit Care Med 1995; 152: 557-564.

8. Berlin M, Fogdell A, Olerup O, Eklund A, Grunewald J. HLA-DR predicts the prognosis in Scandinavian patients with pulmonary sarcoidosis. Am J Respir Crit Care Med 1997; 156: $1601-1605$.

9. Foley P, Lympany P, Puscinska E, Zielinski J, Welsh $\mathrm{K}$, du Bois R. Analysis of MHC encoded antigenprocessing genes TAP1 and TAP2 polymorphisms in sarcoidosis. Am J Respir Crit Care Med 1999; 160: $1009-1014$

10. Ishihara M, Ohno S, Mizuki N, et al. LMP7 polymorphism in Japanese patients with sarcoidosis and Behcet's disease. Hum Immunol 1996; 51: 103 105.

11. Ishihara $\mathbf{M}$, Ohno $\mathrm{S}$, Ishida $\mathrm{T}$, Naruse $\mathrm{T}$, Inoko $\mathrm{H}$. Genetic polymorphism in intron 6 of the LMP7 gene in Japanese and its association with sarcoidosis. Tissue Antigens 1997; 50: 650-653.

12. Rybicki BA, Maliarik MJ, Malvitz E, et al. The influence of $\mathrm{T}$ cell receptor and cytokine genes on sarcoidosis susceptibility in African Americans. Hum Immunol 1999; 60: $867-874$.

13. Arbustini E, Grasso M, Leo G, et al. Polymorphism of angiotensin-converting enzyme gene in sarcoidosis. Am J Respir Crit Care Med 1996; 153: 851 - 854.
14. Maliarik M, Rybicki B, Malvitz E, et al. Angiotensinconverting enzyme gene polymorphism and risk of sarcoidosis. Am J Respir Crit Care Med 1998; 158: $1566-1570$

15. Pietinalho A, Furuya K, Yamaguchi E, Kawakami Y, Selroos O. The angiotensin-converting enzyme DD gene is associated with poor prognosis in Finnish sarcoidosis patients. Eur Respir J 1999; 13: $723-726$.

16. Tomita $\mathrm{H}$, Ina $\mathrm{Y}$, Sugiura $\mathrm{Y}$, et al. Polymorphism in the angiotensin-converting enzyme (ACE) gene and sarcoidosis. Am J Respir Crit Care Med 1997; 156: $255-259$.

17. Niimi $\mathrm{T}$, Tomita $\mathrm{H}$, Sato $\mathrm{S}$, et al. Vitamin $\mathrm{D}$ receptor gene polymorphism in patients with sarcoidosis. Am J Respir Crit Care Med 1999; 160: 1107-1109.

18. Seitzer U, Swider C, Stuber F, et al. Tumour necrosis factor alpha promoter gene polymorphism in sarcoidosis. Cytokine 1997; 9: 787-789.

19. Somoskövi A, Zissel G, Seitzer U, Gerdes J, Schlaak M, Müller-Quernheim J. Polymorphisms at position -308 in the promoter region of the $\mathrm{TNF} \alpha$ and in the first intron of the TNF $\beta$ genes and spontaneous and lipopolysaccharide-induced $\mathrm{TNF} \alpha$ release in sarcoidosis. Cytokine 1999; 11: $882-887$.

20. Grunewald J, Olerup O, Persson U, Öhrn M, Wigzell $\mathrm{H}$, Eklund A. T-cell receptor variable region gene usage by $\mathrm{CD} 4+$ and $\mathrm{CD} 8+\mathrm{T}$ cells in bronchoalveolar lavage and peripheral blood of sarcoidosis patients. Proc Natl Acad Sci 1994; 91: 4965-4969.

21. Grunewald J, Janson CH, Wigzell H. Biased expression of individual $\mathrm{T}$ cell receptor $\mathrm{V}$ gene segments in $\mathrm{CD} 4+$ and $\mathrm{CD} 8+$ human peripheral blood T-lymphocytes. Eur J Immunol 1991; 21: 819-822.

22. Grunewald J, Janson CH, Eklund A, et al. Restricted $\mathrm{V} \alpha 2.3$ gene usage by $\mathrm{CD} 4+\mathrm{T}$-lymphocytes in bronchoalveolar lavage (BAL) fluid from sarcoidosis patients correlates with HLA-DR3. Eur J Immunol 1992; 22: $129-135$.

23. Grunewald J, Berlin M, Olerup O, Eklund A. Lung T-helper cells expressing T-cell receptor AV2S3 associate with clinical features of pulmonary sarcoidosis. Am J Respir Crit Care Med 2000; 161: 814-818.

24. Katchar K, Wahlström J, Eklund A, Grunewald J. Phenotypic analysis of lung accumulated CD4 positive $\mathrm{T}$ cell expansions expressing T cell receptor AV253 in Scandinavian patients with pulmonary sarcoidosis. Am J Respir Crit Care Med 2001; (in press).

25. Grunewald J, Hultman T, Bucht A, Eklund A, Wigzell $H$. Restricted usage of $T$ cell receptor $V \alpha / J \alpha$ gene segments with different nucleotide but identical amino acid sequences in HLA-DR3 + sarcoidosis patients. Mol Med 1995; 1: 287-296.

26. Löfgren S. Primary pulmonary sarcoidosis. Acta Med Scand 1953; 145: 424-465. 